The Spectrum of

\title{
NREL Uses Computing Power to Investigate Tidal Power
}

\section{Researchers at the National Renewable Energy Laboratory (NREL) have applied their knowledge of wind flow and turbulence to simulations of underwater tidal turbines. Inspired by similar simulations of wind turbine arrays, NREL researchers used their wind expertise, a supercomputer, and large-eddy simulation to study how the placement of turbines affects the power production of an underwater tidal turbine array.}

As tides ebb and flow, they create water currents that carry a significant amount of kinetic energy. To capture this energy, several companies are developing and deploying devices known as horizontal-axis tidal turbines, which resemble small wind turbines. These devices can be arranged in an array of multiple turbines to maximize the energy extracted in tidal regions. But because tidal turbine arrays are relatively new, there is still much to learn about their flow physics and energy capture capabilities. Although valuable, it can be costly and difficult to conduct field experiments in a tidal environment.

Researchers from the National Wind Technology Center, located at NREL, used computational fluid dynamics (CFD) — a computer tool for predicting the way in which fluids flow by numerically solving the equations of fluid motion - and a high-performance computing system. They simulated various turbine array configurations by employing large-eddy simulation, a method for representing turbulence that they had previously used for analyzing wind turbine arrays.

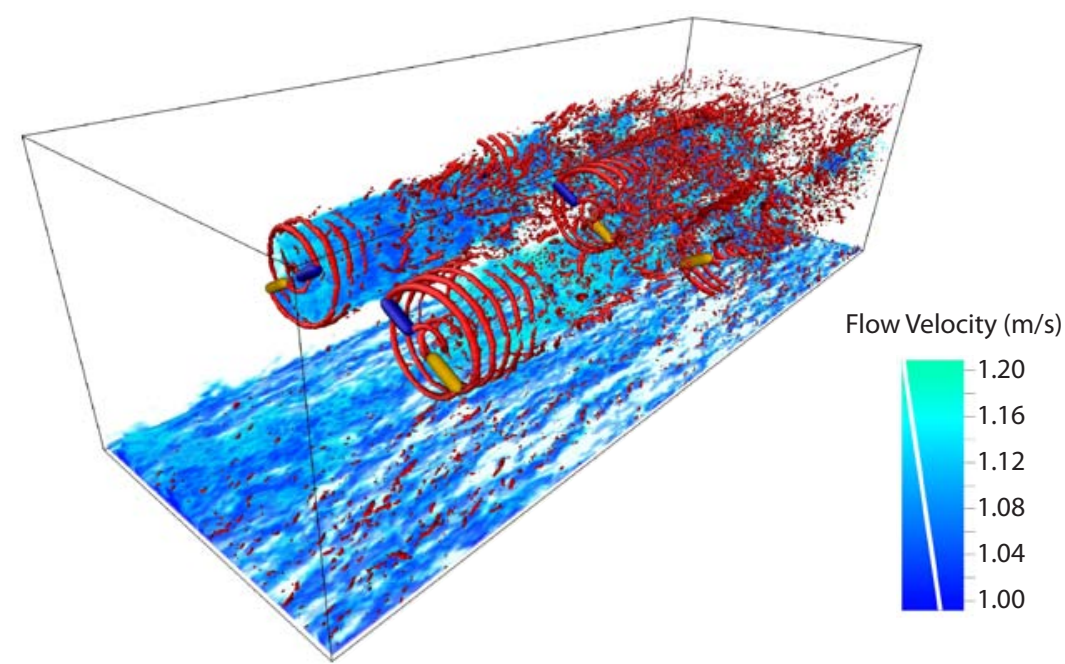

A visualization of data from a large-eddy simulation of the flow of water through an array of tidal current turbines shows the low-speed flow (blue) in the turbine wakes and near the bottom of the tidal channel. Vortices caused by the turbine blades are shown in red, spiraling behind the turbines. In this simulated array, the turbines within a row are staggered, and each turbine rotates in the opposite direction of its upstream neighbor. Illustration by Matt Churchfield, NREL
Clean Energy Innovation

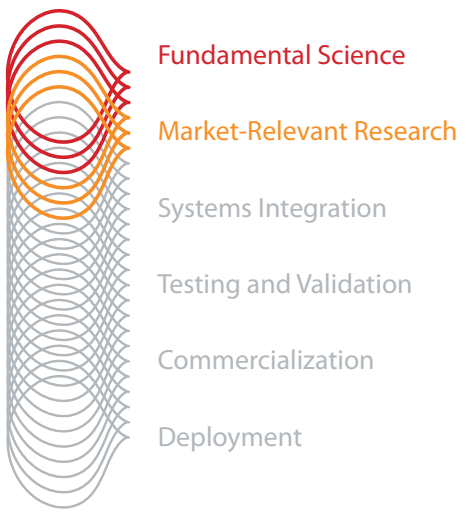

Through deep technical expertise and an unmatched breadth of capabilities, NREL leads an integrated approach across the spectrum of renewable energy innovation. From scientific discovery to accelerating market deployment, NREL works in partnership with private industry to drive the transformation of our nation's energy systems.

This case study illustrates NREL's innovations in Fundamental Science through Market-Relevant Research
NREL is a national laboratory of the U.S. Department of Energy, Office of Energy Efficiency and Renewable Energy, operated by the Alliance for Sustainable Energy, LLC. 
Large-eddy simulation provides a time-accurate, high-resolution look at fluid behavior. The similarities between wind and water - both of which are fluids, although one is air and the other liquid-inspired these researchers to apply large-eddy simulation to tidal turbine arrays. For both wind turbine arrays and tidal turbine arrays, largeeddy simulation captures the important large turbulent eddies that affect instantaneous turbine power output, as well as the low-energy turbine wakes that meander downstream and affect the next row of turbines in an array. The data generated using large-eddy simulation provides a better understanding of how to best situate the turbines to achieve the highest energy output while minimizing fatigue loads.

One variable in the placement of turbines within an array is the spacing between consecutive turbines within flow-aligned rows. Turbines in flow-aligned rows encounter the wakes of upstream turbines. These "waked" turbines do not produce as much power as "unwaked" turbines because there is not as much energy to extract from wake flow as from undisturbed flow. But over longer distances, turbulence mixes the higher-energy, undisturbed surrounding fluid with the lower-energy wake fluid, re-energizing the flow.

NREL researchers simulated different turbine spacings and found that expanding the spacing from 4 to 6 turbine rotor diameters increased the array's overall efficiency from $78 \%$ to $84 \%$, because the downstream turbines were subject to more re-energized wake flow. The array's efficiency is the ratio of the total power produced by the array to the power that would be produced by the same number of isolated turbines, so it is a measure of how turbine interactions affect the performance of the array. Researchers also observed a 3\% array efficiency increase when the downstream waked turbine rotors rotated counter to the next upstream turbines' rotors.

But of all the different criteria studied, it was the staggering of consecutive tidal turbines that had the greatest impact on array efficiency. By laterally offsetting consecutive turbines in a flow-aligned row, downstream turbines effectively became unwaked. In fact, the staggered turbine array performed at 104\% efficiency, meaning its collective power production was larger than that of the same number of isolated turbines. This is because the water accelerates between upstream turbines, and the downstream staggered turbines directly encounter this accelerated flow. Such a turbine layout scheme is feasible in bi-directional flows like those of a tidal channel.

The research demonstrated that it is possible to apply the simulation tools of one type of renewable energy technology to another. The study also confirms that largeeddy simulation is a useful but computationally intensive tool for investigating tidal turbine array phenomena.

NREL researchers intend to further examine other influences on tidal turbine array efficiency and mechanical loads, including the impact of different turbulence levels in the tidal streams. Such turbulence depends on the water speed, temperature and salinity stratification, and local tidal channel topography. Ultimately, NREL researchers hope that the knowledge gained in this study can be used to improve or create a simpler simulation tool that can be used by developers to analyze and plan efficient tidal turbine arrays.

\section{Tapping into the Waves and Tide as a Renewable Resource}

Anyone living near the ocean knows that waves and tides can be powerful forces, but they also represent a large potential source of renewable energy. According to a 2011 report produced by the U.S. Department of Energy (DOE) and Georgia Tech Research Corporation, waves and tidal currents along U.S. coasts could produce 1,420 terawatt-hours of electricity per year-approximately one-third of the nation's total annual electricity use.

The report, Assessment of Energy Production Potential from Tidal Streams in the United States, also revealed where the best wave and tidal energy resources are located in the United States, with Alaska topping the list as having the most promising sites. The next best resources were found in Maine, Washington, Oregon, California, and New Hampshire.

To harness the energy from these resources, many companies worldwide are beginning to commercialize marine energy devices such as tidal turbines. For example, Verdant Power deployed tidal turbines in New York City's East River, and was the first U.S. company to receive a commercial license for tidal power.

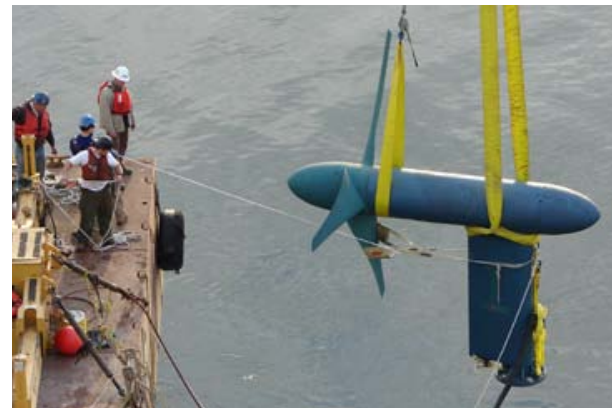

Verdant Power's tidal turbine being deployed in the East River. Photo from Verdant Power, NREL/PIX 17209

\section{National Renewable Energy Laboratory}

15013 Denver West Parkway

Golden, CO 80401

303-275-3000 • www.nrel.gov

NREL is a national laboratory of the U.S. Department of Energy, Office of Energy Efficiency and Renewable Energy, operated by the Alliance for Sustainable Energy, LLC.

NREL/FS-6A42-55613 • October 2012

Printed with a renewable-source ink on paper containing at least $50 \%$ wastepaper, including $10 \%$ post consumer waste. 